\title{
The Role of Public Universities: Examining one university's response to xenophobia
}

\author{
JUDY FAVISH
}

$\mathrm{O}$ 19 May 2008 South Africans woke up to the horrifying image of a Mozambican man, Ernesto Nhamuave, engulfed in fire. Upon investigation, it turned out that he had been set alight by fellow human beings. Professor Adam Habib, Deputy Vice-Chancellor of the University of Johannesburg, has described Ernesto Nhamuave as the human face of South Africa's orgy of xenophobic violence (Habib 2008). He died in the Ramaphosa informal settlement after a group of South Africans beat him, doused him with petrol and burnt him alive.

Ernesto was one of the 65 or more foreign nationals who would die in the following days in the violence that swept Gauteng. Thousands more fled their homes with literally nothing except the clothes on their backs. By the end of the week, the violence had spread like wildfire throughout the country. This unprecedented violation of the rights of 'others' in South Africa bordered on human catastrophe and caught the government, public institutions and individuals by surprise - people did not know how to respond. 
Many South Africans volunteered their time and energy to help the displaced people. The University of Cape Town (UCT), home to 2308 students from the rest of Africa, did react to the crisis, but in a manner that suggested that UCT was grappling with appropriate ways of translating its commitment to being an engaged university into concrete action.

UCT's immediate response to the xenophobia crisis took the form of humanitarian aid designed to mitigate the suffering of thousands of people displaced by the violence. Professor Martin Hall, then Deputy Vice-Chancellor at UCT and co-chair of the UCT Crisis Response Committee that was set up to co-ordinate the support of the UCT community, described the university's response as follows:

It became clear on about the Wednesday that there was a rapidly emerging crisis in Cape Town. On Friday evening UCT was told that there were 200 people displaced in buses. UCT's initial reaction was to find accommodation for these people. So the first response was to find 200 mattresses, which the residences did magnificently and very quickly. At first we thought we would need the Sports Centre. But soon after that we were advised that the network of church halls and community centres would be able to cope with the flood of displaced victims. So the people who we thought were coming to us were diverted into what eventually turned out to be a network of over 100 community sites. So we then sent the mattresses that we collected to the church. We were informed that the most immediate role we could play was providing transport for people who had been forced to leave their homes. So we deployed the Jammie Shuttles and moved about 2000 people in the course of the weekend. Staff and students were also mobilised to provide relief in the form of blankets, clothing and food. SHAWCO [Student's Health and Welfare Centre Organisation] volunteers conveyed the goods to various distribution points that had been set up by non-governmental organisations (NGOs) and the churches. (Hall 2008)

During the course of the crisis, UCT's contribution increasingly came to reflect the particular expertise and strengths that reside within the university, manifested across a diversity of activities. Students were mobilised to assist in various ways. In UCT's case the capacity to do this quickly and effectively was due to the volunteer 
infrastructure established by SHAWCO, a community development organisation run by students of UCT. As well, the resources of medical personnel were speedily galvanised through the Health Sciences Faculty. Another set of resources was located in the Refugee Rights Project, attached to the Law Faculty. Staff from the clinic there had been working with refugees for years and, as a result, had the infrastructure and relationships to respond to the incidences of human rights abuses and provide advice on protocols for dealing with refugees. And finally, the Department of Social Development mobilised its resources to offer counselling services.

Whilst it is recognised that many other departments in UCT organised seminars on xenophobia, or introduced discussions on xenophobia into formal teaching programmes, this article focuses on the interventions of SHAWCO, the Refugee Rights Project and the Department of Social Development. These initiatives were nominated by the faculties and student society representatives on the Social Responsiveness Working Group for inclusion in the 2008 Social Responsiveness Report. Representatives from these units were also represented on the Vice-Chancellor's Crisis Response Committee.

\section{SHAWCO: SUPPORTING HEALTH RELATED INTERVENTIONS}

SHAWCO Health Sector is an arm of SHAWCO that is run by Health Sciences students on a voluntary basis. It provides six evening clinics on a weekly basis and one paediatric clinic every month to seven disadvantaged communities in the Cape Metropolitan area.

On the evening of 23 May 2008, a member of the SHAWCO Health Steering Committee received a phone call from one of the volunteer doctors who was helping out at the Caledon Street Police Station in the city to ask whether SHAWCO volunteers could assist with handing out blankets, food, and clothes to the thousands of people who had been displaced by the violence and had congregated at the police station. A decision was made to advertise the need through SHAWCO's regular communication channels. The communication indicated that volunteers would help as individuals, not under a SHAWCO umbrella, since SHAWCO could not take responsibility for the safety of volunteers in this situation. A bulk sms was sent out at 22:45 to the 300-plus students on the SHAWCO health database, requesting their help. 
On Saturday morning an emergency meeting was called for SHAWCO Health Steering Committee members and other SHAWCO leaders from the SHAWCO Education Sector on the university's main campus to decide how SHAWCO could help. It was decided that SHAWCO Health would focus on health-related activities, while SHAWCO Education, with the aid of SHAWCO staff and drivers, would co-ordinate the collection and distribution of large amounts of food, clothing and hygiene products to the different sites of refuge. This enabled a large portion of the UCT community to get involved personally and practically. A decision was also made that SHAWCO would not use its branded vehicles to take relief items into the communities that SHAWCO traditionally serves.

SHAWCO has struggled to change its brand from a welfare organisation to a development organisation over the last 14 years, with communities still expecting free handouts of food and clothing. We did not want communities to feel that we had double standards, but we did want to contribute in some way to an unprecedented crisis. A further decision was made that SHAWCO Health would not suspend any of its normal services - a move which could potentially have generated xenophobia where none had existed previously by making our normal communities feel marginalised during the crisis. (De Wit \& Lewin 2008)

On the Saturday night, 24 May, SHAWCO Health leaders met with members of the Treatment Action Campaign (TAC), AIDS Law Project (ALP), AIDS \& Rights Alliance for Southern Africa (ARASA), Médecins Sans Frontières (MSF) and individual doctors to discuss a concerted health response. A decision was made to run a health assessment across all known sites on Sunday morning, utilising a rapid needs assessment tool developed by MSF, the site details accumulated by TAC, and volunteers mobilised by SHAWCO Health:

A sms was sent out at 21:30 on Saturday night asking for volunteers to report at 08:00 the next morning. Despite the last-minute call and early wake-up, 20 volunteers arrived the SHAWCO offices the next morning. The volunteers from the Faculty of Health Sciences included medical and health and rehabilitation students. The volunteers were trained by MSF and given instructions on security issues. Four students were paired up with doctors and the rest worked in student-pairs. 
A total of 18 sites had been identified for the teams to visit that day - they came back with over 33 having been assessed (as a team would go into an area, the police would take them to more sites which had not as yet requested help from the civil society coalition). SHAWCO volunteers wore SHAWCO Health shirts so that they would be identified as relief workers. Through this identification, SHAWCO became the link between the civil society coalition and various church groups who were hosting internally displaced people. By the Monday after the crisis exploded the churches were running an online database of all the sites which they were supporting. SHAWCO Health was able to feed information into these sites, as well as to incorporate health-specific questions, needs and information so that the overall response could be more effective. (De Wit \& Lewin 2008)

By Sunday afternoon, 25 May, over 33 sites had been surveyed and information from all those sites captured and assessed, which was then relayed to various role-players in the response. The survey captured information on, inter alia, numbers of men, women and children, shelter, food provision, health needs, health services and safety. This was the first data obtained regarding the extent of the crisis situation. Up until this point, the City of Cape Town had no idea of the scale and complexity of the situation. The framework developed on this day was later adopted by the City of Cape Town Disaster Management Team as a basis for monitoring all sites. Subsequent modifications were made by the Civil Society Coalition (CSC), a loose network of community based organizations and NGOs that was formed to facilitate a co-ordinated response to the crisis. These modifications included questions on the provision of health services in the area, visits of health officials, and access to first aid at the sites.

On Monday, 26 May, in a meeting between city and provincial health leaders and representatives of the Civil Society Coalition, it was agreed that daily health assessments would be run by health officials across the eight health sub-districts in the Cape Metro area, and the results of these assessments would be sent to the CSC along with requests for volunteers aimed at specific interventions. While waiting for the information from the health services to come through, UCT's Faculty of Health Sciences and SHAWCO Health, in 
partnership with the TAC/ALP / ARASA-convened alliance, began putting together a database of students and staff members who were willing to help with health-specific interventions.

It was a very effective use of the faculty's communication systems and SHAWCO's long-standing ability to co-ordinate volunteers. (De Wit \& Lewin 2008)

As per the agreement, the details of the individuals willing to help were sent to the health authorities. By the Thursday of that week, 29 May, the CSC, still waiting for a response from the health authorities, decided it was necessary to run another rapid site assessment of the more than 70 sites that were now logged on the central database. SHAWCO volunteers from upper campus formed part of the group that ran these assessments, as SHAWCO's health students were occupied with their curriculum work in the hospitals during the weekdays.

From the information gathered through the rapid needs site assessment, SHAWCO Health could identify which sites had:

- no access to health care facilities

- large numbers of people

- a large proportion of children under the age of 5 and/or

- signs of diarrhoea and scabies outbreaks.

Although the plan was not to set up parallel health systems, it had become clear from the data gathered that many people were either too scared to access the normal health care facilities or had actually been harassed by local citizens on attempting to access these facilities. SHAWCO Health therefore identified eight sites most in need of extra health services and began to arrange for their mobile clinics and teams of students and doctors to go out and run weekend and evening clinics.

Once again, SHAWCO Health was able to make use of the faculty's bulk sms system to advertise the clinics to all the health sciences students. This enabled SHAWCO Health to have access to students who would not normally be in the SHAWCO communication network and boosted clinic attendance. (De Wit \& Lewin 2008)

SHAWCO Health also developed and distributed materials to help site co-ordinators identify and treat diarrhoea, scabies and TB outbreaks, as well as information on medical 'red flags' - what to 
refer, how quickly, and to where. None of this kind of information had been distributed during the first week of the crisis. This was later added to by a leading paediatrician and academic who put in special notes on how to care for newborns, nutrition, and handling of specific childhood illnesses. These resources will be kept on file for any similar crisis that might arise in the future. Over the space of the week, SHAWCO Health ran nine clinics at eight different sites around Cape Town, treating over 600 people (in addition to the six normal evening clinics on Mondays, Tuesdays and Wednesdays). A later clinic was run by volunteer doctors using one of SHAWCO Health's fully equipped mobile clinics and the SHAWCO dispensary for the hundreds of asylum seekers staying under the Eastern Boulevard Bridge (the students were at this time writing end of block exams).

The manner in which the Faculty of Health Sciences and SHAWCO Health worked together to respond to the crisis serves as a wonderful model for how student organisations and more 'institutional' bodies can work together extremely effectively. Each did what they do best and supported each other, which led to a highly efficient health response from the UCT community. (De Wit \& Lewin 2008)

Refugee RIGHTS PROJECT: HELPING TO MANAGE A HUMANITARIAN CRISIS On the morning of Friday 23 May, the Refugee Rights Project fielded calls from countless numbers of its fear-stricken clients who were afraid to leave their homes as well as from others who were confronted by perpetrators of violence. The Refugee Rights Project staff immediately intervened by liaising with the South African Police Service to assist those affected to reach places of safety.

Later that day nearly 250 refugees arrived at the offices of the Refugee Rights Project at the Law Faculty seeking assistance. With severely traumatised clients who obviously needed emergency relief, the staff at the Refugee Rights Project had to step outside their traditional role of attorneys to manage a humanitarian crisis. With the assistance of the Rondebosch Police, initially at the police station and later at Rondebosch United Church, they managed to place 1057 refugees in shelters in and around Cape Town with the Jammie Shuttle providing much needed transportation.

On Saturday morning the project staff logged all the displaced people that were assisted by them with the Cape Town Disaster 
Management Team. Many members of the UCT community (staff and students) came to the assistance of the project staff.

It soon came to the attention of the Refugee Rights Project that refugees who were housed at community halls, church halls and mosques were being moved by government to the Youngsfield Military Base as well as other distant and relatively remote places such as Soetwater and Silverstroom. Within hours it became apparent that refugees' rights were being violated by the military personnel and other officials at these sites.

The Refugee Rights Project immediately intervened by liaising extensively with the military personnel at the base, explaining the refugees' right to freedom of movement, amongst others. This intervention directly resulted in these rights being respected and in the media gaining access. (Khan 2008)

Other legal issues immediately identified and addressed by the project were the forced and undignified tagging of the refugees at these sites and the attempted unlawful registration of people not already documented. It was pointed out to the Minister of Home Affairs (in a series of correspondence), under whose ostensible authority this was being done, that the authority she claimed for the procedure did not in fact empower such registration and that the offensive questions on these registration forms had no basis in law. This led to the minister retracting the initial unlawful registration and relying rather on powers under the Immigration Act to grant residence to the undocumented migrants for a six-month period. During this time, much appreciated support and assistance for the refugees came from the staff at the Refugee Rights Project and, indeed, from the entire Cape Bar, an association of attorneys and advocates.

At the same time refugees were demanding involvement from the office of the United Nations High Commissioner for Refugees in Cape Town (UNHCR). Project staff convinced UNHCR staff to come to Cape Town and establish a presence for the duration of the crisis. In addition they also facilitated many meetings with community-based organisations and NGOs and the UNHCR protection unit.

A very important role identified by the Refugee Rights Project staff during this time was the fact that they, via their clients, were a 
key source of information, and at times of life-saving information. During the crisis of May 2008, they informed the South African police of the impending attacks on foreigners and the exact areas where such attacks were likely to occur, thus helping to ensure that not a single person was killed in the Western Cape. They did so again in September 2008 in an attempt to avert further brutal attacks and displacement of vulnerable people whom the entire international community had agreed to protect.

The Project staff remain committed to ensuring that refugees' rights are not violated and in this regard they continue to inform South Africans about refugee rights.

DePARTMENT OF SOCIAL DEVELOPMENT: RENDERING PSYCHOSOCIAL SUPPORT

Concerned about the unfolding crisis, staff in the Department of Social Development acted quickly when approached by the Dean of the Faculty of Humanities on 26 May 2008 about offering services to refugees. Initial responses included compiling a list of volunteers to render psychosocial support to displaced refugees. The department recognised that even though direct counselling was not part of its core activities these were extraordinary circumstances and the values of the social work profession dictated that staff respond to this human disaster. The department was also aware that its students worked in communities as part of their field practice and that they may be placed in situations where they needed to respond to clients who were traumatised as a result of the events. The goals of the department were to:

- render psychosocial support to individuals and groups affected by violence and displacement

- participate in networks with community service organisations (CSOs) and UCT staff in order to pool resources so that services could be maximised and

- identify lessons in reframing practice-based interventions from African experiences of displacement.

The first step was to compile a list of potential volunteers, which consisted of staff and students in the department, colleagues from the Psychology Department and practitioners in the field. The project coordinator, with the assistance of the head of the department, liaised with SHAWCO and a meeting was convened with Dr Pumla Gobodo- 
Madikizela, from the Department of Psychology, to plan a response.

Counselling was conducted with groups and individuals, but it soon became clear that the refugees were being further traumatised by a lack of co-ordination between the province and the city. This resulted in confusion around what was going to happen, an overreliance on volunteers, and the absence of a clear idea as to how the government planned to deal with the situation.

Based on ongoing needs assessments, the method of intervention was modified and counselling was offered on an ad hoc basis. It soon became evident that refugees were preoccupied with meeting their basic needs and that the most practical way to offer support was for a counsellor or counsellors to be available at specific times. Counselling rosters were compiled for Youngsfield and Harmony, which were advertised via the leaders and the refugees used the service as needed. It was also clear that services needed to be offered during the day as well as after hours, because the majority of displaced persons at both sites were not available during the day. The adults would leave the sites to go and seek employment and the children attended school.

At Chrysalis Academy, services were offered during the day only (including Saturdays). However, a volunteer was available at night in the event of an emergency. Later, at Summer Greens, a counsellor was available two mornings per week and three counsellors were available four evenings a week. Counsellors offered support to mainly adult refugees, but some support was provided to children. They also offered support to volunteers who were showing strain as a result of working long hours and not being able to answer the refugees' questions about their future. Volunteers were feeling helpless and despondent.

In the third week of the crisis the department realised that Chrysalis Academy was reasonably well resourced in terms of counsellors and approached the Network of Trauma Support Providers to find out where the department's assistance was needed more. The department then decided to render services at the Summer Greens Hall, which was housing a total of 250 people, including 65 young children. The situation at Summer Greens was different in that the site was co-ordinated by the refugees themselves and there were 
very few volunteers who were involved. However, the leaders of the site also required support. The service during the day was geared towards adults, whereas the evening sessions were mainly used to intervene with children.

The counsellors realised that the classic role of therapist would not suffice in this situation and that intervention was required at different levels. This included organising food, linking with government officials about the provision of basic needs, assisting with tracing lost relatives, and organising medical assessments and treatment.

A positive development at the onset of the intervention was the establishment by the Health Sciences Faculty of the Network of Trauma Support Providers, mentioned above. This informal network consisted of academics, CSO staff and private practitioners. The network enabled co-ordination between the departments of psychiatry, psychology and an NGO, the Trauma Centre for Survivors of Violence and Torture.

\section{RefLections on the PUbLic ROLE OF THE UNIVERSity}

As can be seen from the above accounts, the UCT response took the form of humanitarian aid with students and staff from the UCT community contributing predominantly as concerned citizens. In addition, academics and students provided specialised services linked to their professional areas of competence or fields of study.

At the meeting which took place on Monday, 26 May, to which all members of the UCT community were invited, a strong view was expressed that UCT needed to move beyond its 'first response' of humanitarian aid and focus on developing a deeper understanding of the causes of the crisis with a view to formulating proposals for more effective immigration policies and state responses to the gross violations of human rights which had occurred all over the country.

The key challenge identified was for the university to formulate a framework for a sustained long-term intervention without prescribing what form the intervention should take. The motivation for intervening probably stemmed from a desire to support the role of public universities in promoting the public good and helping to address development challenges faced by our society in line with UCT's mission to play 'an active developmental role in our cultural, economic, political, scientific and social environment’ (UCT 1996). 
The activities of the Department of Social Development illustrate how a department in a university can position itself to engage with long-term issues. From the outset the department decided to set academic goals for its intervention, because ultimately it aimed to reflect on the lessons learnt from the experience and incorporate these lessons into its teaching as well as encourage debate about the practice models used:

The work with displaced refugees is vital, not only for humanitarian reasons, but because it will inform the teaching of the Department of Social Development. Historically the department has always recognised the relevance of incorporating input on trauma into the curriculum. The trauma and struggles experienced by refugees is a strong component of the module on Trauma Intervention offered by the department.

The work with refugees provided staff with the opportunity to conduct research on issues related to xenophobic violence. Our postgraduate students in Development Planning were tasked with examining planning processes related to the re-integration of refugees into communities. Staff have continued to be involved in ongoing research into the dynamics and struggles faced by displaced persons in the Cape Metropole area. The department will also be hosting a seminar with relevant stakeholders to examine our intervention and to debate practice models, learnings and the way forward. It is also envisaged that the papers discussed at this seminar will be published. (Williams 2008)

The Religion and Xenophobia Conference organised by the Religious Studies Department is another example of an initiative designed to stimulate debate about the underlying causes of the xenophobia crisis and to reflect on strategies for addressing these.

However, whilst other departments within the university may have engaged in a similar fashion, once the need for large-scale humanitarian aid declined, it proved difficult to sustain a centrally co-ordinated initiative to engage with the long-term challenges. Hall suggests that one of the major reasons for this stems from contestations, or a lack of clarity, about the public role of the university: 
The extent to which the university interprets its public role beyond the core issues of research and teaching provision is an unsettled issue in higher education. What is interesting in the sort of situation that we faced in this crisis is that the more theoretical policy issues which have been there in an abstracted sense all the time became very concrete. For example, we've always known that the 1997 White Paper identifies a clear set of public obligations for universities. But it's one thing to debate those in the abstract; it's another thing altogether to know how to respond to a very immediate public crisis. So UCT's decision to set up the Crisis Committee was essentially reactive rather than proactive, and a result of a buildup of voices within the institution urging the institution to do something. This created a collective push towards an engagement. (Hall 2008)

The difficulty in sustaining a longer-term intervention highlighted structural difficulties in regard to promoting the civic mission of universities. As Hall says:

UCT's organisational structure is set up to reproduce and extend a core of largely discipline-based knowledge through discipline-based teaching and discipline-based research. I have no doubt that that sort of work has a key role in an education system as a whole. But to seriously address the challenges that manifested themselves during the xenophobia crisis would require strong, clear and directed university leadership working in consultation with the entire university community. Such leadership would enable the university to draw on the strengths of individual departments, whilst seriously grappling with the implications of being a university located in one of the steepest gradients between wealth and poverty in the world.

So whilst there is a large number of motivated individuals and groups of individuals across the university who are very passionate about human rights issues, and who may from time to time demand that the university responds as an institution to particular strategic issues, there isn't an organisational structure within UCT that can carry or own a university-wide project. This becomes more challenging when long-term interventions necessitate inter-disciplinary work. There's no funding available, there's no organisational structure that you could use, and so it is likely to be entirely champion dependent. (Hall 2008) 
In explaining the motivation for his own involvement, Hall refers to the connection with his transformation portfolio:

The crisis was highly racialised, and appeared to be related in complex ways to issues of inequality, social exclusion and poverty. Although the nature of the linkages still needs to be analysed properly, there was sufficient evidence to suggest that the causes reflect the pathologies of poverty, inequality and exclusion, which are substantive issues of transformation. I therefore felt that addressing the crisis was part of my portfolio.

Given that disciplines constitute the basis of the organisation of universities, the lessons from UCT's engagement in the xenophobia crisis suggest a critical role for the university leadership in allocating appropriate resources to:

- harness intellectual expertise from across the university

- deepen debate about the causes of a crisis such as the xenophobic violence and

- critically reflect on long-term strategies for addressing these underlying causes

The need for a university-wide response reflects the importance of inter-disciplinary collaboration in building better understanding of complex phenomena:

Really interesting things happen when people from different disciplines get together to discuss issues. There are key human rights questions, which are not necessarily straightforward - there are people who would come out of law who would believe in absolutist versions of human rights, which will be completely challenged in anthropology. So it can be argued where problems are as complex as those associated with the xenophobia crisis, university-wide debates and discussions could have contributed to a deeper understanding of the issues.

(Hall 2008)

\section{Promoting CRITICAL CITIZENSHIP}

Much of the literature on the public engagement of universities refers to the role of universities in producing critical citizens through educational programmes and practices that are conducive to critical discourse, cultural tolerance and a common commitment to a humane and just social order. 
Fulfilling this mission entails the provision of opportunities for ongoing debate about various forms of prejudice and humanitarian disasters, amongst other things, so that students are equipped to deal with such challenges in the future.

In the absence of a university-wide structure to organise public debates, universities tend to rely on individual champions or academics who take their roles as public intellectuals very seriously.

UCT was fortunate to be able to draw on the reservoir of expertise within SHAWCO and its network of student volunteers to recruit volunteers to assist with the relief effort. Indeed, the role played by SHAWCO illustrates how critical the existence of a student-run entity like SHAWCO at a university can be, both for building relationships with local communities in Cape Town and for providing students with opportunities for co-curricula experiences which enable them to acquire leadership skills, whilst addressing key development challenges facing our society. Student volunteers who participate in SHAWCO activities attest to how their engagement with communities strengthens their commitment to promoting a culture of tolerance and social justice within the country. They also come to appreciate the importance of team work and the value of social networks in addressing major challenges facing South Africa:

I think a large part of why SHAWCO's response was successful was because it was student-run. Yes, staff members were there to offer support and assure students that there was a budget which they could draw from, but essentially the students were given free rein to respond in the way they saw best. I believe it is because of this freedom that they responded in such an overwhelmingly professional and effective manner - I think, had we as staff members assumed responsibility and told them what to do, we would have had a totally different situation on our hands. Students have personal resources in terms of energy and idealism, but also in terms of their communication and social networks and (I know this is the wrong word, but) a 'moral authority' because they are acting in a voluntary capacity and not as part of their ' job'. So, when a student asks another student to come and help out, there is more clout and communication to other students than when a student is asked/ told by a staff member or as part of the university's structures. 
While the university may have tried to tap into residences for donations and volunteering, it was actually the students who came up with the idea of contributing their meals (yoghurts, packed sandwiches, juices, etc.) to the sites, as well as ongoing collections (and marketing of the collections) of clothes and hygiene products. These were individuals in individual residences who took the initiative to do this on their own volition. (Lewin 2008)

Whilst this quote from a staff member at SHAWCO highlights the importance of student-led initiatives in nurturing a life-long commitment and sense of responsibility to contributing to the development of society, it also challenges the university to reflect critically on whether sufficient opportunities are provided for students to acquire the practical skills needed for active citizenship through the formal curriculum or as part of the co-curriculum. As a member of the SHAWCO Board says:

Students who volunteer via SHAWCO do so primarily in their capacity as UCT students. So it is difficult to see how SHAWCO could operate independently of UCT. But I think it is important to reflect on the extent to which 'UCT's response' was so critically dependent on SHAWCO, which, although closely linked to UCT, is in fact a largely independent NGO. Thus, for instance, how different would the picture have been in the absence of a SHAWCO? And what might the implications of this be? I think it is important to think about what it all means for how the UCT community is mobilised, not only in crisis situations, but also to respond to ongoing social needs in the communities of which we are a part. The reliance on SHAWCO to provide a channel for student volunteerism, given its ambiguous relationship with the university, exposes potential weaknesses within UCT with respect to the role of universities in providing opportunities for students to acquire skills associated with active citizenship through practice. I believe that the role that SHAWCO plays currently in UCT is not fully appreciated. (Molteno 2008)

\section{Conclusion}

The brief accounts of the contributions of SHAWCO, the Refugee Rights Project and the Social Development Department indicate the enormous capacity that exists within universities to contribute to the 
ongoing development of our society, through research and teaching, as well as through sustained engagement with issues confronting our country. However, the case profiles suggest that universities need to grapple seriously with the challenge of building the relationships and structural mechanisms that will enable them to enhance their role in promoting the public good. It also raises questions about the critical role of university leadership in developing appropriate strategies for promoting inter-disciplinary collaboration and galvanising the intellectual resources of the university to respond to the needs of the majority of people in our country.

The benefits of promoting a culture of volunteerism amongst students have been highlighted, as well as the need for the university to reflect on appropriate protocols for mobilising the resources of SHAWCO and other student-led societies.

Lastly, the positive features of the collaboration between students and staff of the Health Sciences Faculty, and between them and other organisations of civil society, provide excellent examples of the ways in which mutually beneficial relationships can be built with external constituencies. As Lewin and De Wit say:

Imagine if each faculty and structure in the university (such as residences etc.) had called its students together on the first day and asked them to identify ways in which they could respond, firstly within the line of work they are studying (if possible), secondly with the faculty's resources (such as communication structures, phone lines, people, computers etc.), and thirdly just with the faculty's support (just knowing their students were going out as a group to play games with kids in the camp, for instance, and encouraging them in different ways). If the student leaders in residences had been given the space and support of the organisation's structures to mobilise donations, volunteers etc. - can you imagine each residence committing to sending out ten volunteers to run afternoon classes with kids in the camps, or something? How awesome would that have been?

Admittedly, this all took place during and after exams, but we believe that if universities more actively promote and recognise what 'student organisation' can accomplish, we would have seen a lot more of it. Then, in ten year's time, if something like this hit again, we would have doctors, lawyers, biologists, 
engineers, business people, musicians, sociologists, playwrights etc. all knowing a little more about how to respond to this situation, and wanting to respond to the situation, because they know that it is each individual that counts, not just the name of an institution.

\section{REFERENCES}

Information for this case profile was provided by: Ms Thandi de Wit, Ms Fatima Khan, Mrs Wendy Lewin, Mr Frank Molteno, Ms Fatima Williams and Associate Professor Allan Taylor; from an interview conducted with Professor Martin Hall on 16 October 2008; and from a group interview conducted with Mr Jon Hodgson, Mr Jonathan Hoffenberg, Mrs Wendy Lewin, Mr Frank Molteno and Ms Fatima Williams on 30 October 2008.

Habib, A 2008, 'Explosion of a dream deferred', Cape Argus, 17 June.

University of Cape Town 1996, 'Mission statement', University of Cape Town, Cape Town; see http:// www.uct.ac.za/about/intro 